\title{
Influence of local air velocity from air conditioner evaluated by salivary and skin biomarkers
}

\author{
Masaki Yamaguchi $^{\mathrm{a}^{*}}$, Takayuki Takahashi ${ }^{\mathrm{a}}$, Yuichiro Yoshino ${ }^{\mathrm{a}}$, Makoto Sasaki $^{\mathrm{a}}$, Hajime Nishimiya ${ }^{\mathrm{b}}$ \\ ${ }^{a}$ Graduate School of Engineering, Iwate University, 4-3-5 Ueda, Morioka, 020-8551, Japan \\ ${ }^{b}$ Asahi Kasei Homes Corporation, $R$ \& D Laboratories, 2-1 Samejima, Fuji, Shizuoka, 416-8501, Japan
}

*Corresponding author. Tel./fax: +81-19-621-6349.

E-mail address: masakiy@iwate-u.ac.jp (M. Yamaguchi).

http://www.mech.iwate-u.ac.jp/ yamaguchi/ 
Abstract -The purpose of this paper is to reveal both the psychosomatic and the physical effects of local air velocity from an air conditioner using biomarkers which can be collected noninvasively. Salivary $\alpha$ amylase activity (SAA) and salivary cortisol were used as the indexes of psychosomatic effects. The total protein (TP) collected from stratum corneum was used as an index of the physical condition of dry skin. A continuous experiment over a 5 days period in summer was conducted using 8 healthy young male adults for 2 -types of airflow conditioners, a whole ceiling-type air conditioner (without local air velocity) and a normal-type air conditioner (with local air velocity). The subjects felt cool, windy, dry and uncomfortable when under the normal-type air conditioner as determined in a subjective evaluation. The SAA under the normal-type air conditioner fluctuated more widely than with the whole ceiling-type air conditioner. The level of salivary cortisol decreased more in a day under the normal-type air conditioner than with the whole ceiling-type air conditioner. These results showed that reducing local air velocity may provide more healthy psychosomatic conditions over the long-term. Moreover, the TP of a drying-exposed skin area showed a significant change during this experiment whereas the TP of drying-protected area was relatively unchanged. It was indicated that one week's exposure to local air velocity conditions possibly influences the drying of facial skin. Thus, air movement at low velocity can be provides more comfortable conditions not only psychosomatically but also physically.

Keywords: air conditioner; airflow; biomarker; saliva; stratum corneum; total protein.

Abbreviations used: SAA, Salivary $\alpha$-amylase activity; TP; Total protein. 


\section{Introduction}

In order to maintain thermal comfort and high air quality, air conditioners are used to deliver the amount of supply air into confined spaces. The airflow from them sometimes causes discomfort as a psychosomatic effect and it may affect office work performance [1,2]. It is indicated that even though the development of novel air conditioners such as a heating, ventilation and air-conditioning (HVAC) system may allow for fully automated indoor environment quality (IEQ) control, such systems should not compromise occupants' perception of having some degree of control of their indoor environment [3].

Moreover, the airflow causes dry skin and dry eyes as physical effects. Dry skin has a low level of sebum and can be prone to sensitivity. The skin has a parched look caused by its inability to retain moisture. Various types of novel air conditioners such as a floor-based task conditioner system [4], a floor-standing air conditioner [5] and a task/ambient conditioning system [6-8] have been proposed to provide a comfortable ambient environment. However, the relationship between skin condition and the effects of airflow has not been reported sufficiently.

In order to improve airflow conditions in a living space, the authors have already proposed a whole ceiling-type air conditioner. The novel air conditioner exhaust dispersed airflow from the whole ceiling by using a 3-dimensional knit fabric on the air outlet. Previously, an acute stress evaluation of subjects under the whole ceiling-type air conditioner has been reported using salivary $\alpha$-amylase activity (SAA) as an index of the sympathetic nervous activity [9]. However, a long-term stress evaluation is needed in order to reveal the usefulness of the whole ceiling-type air conditioner. The purpose of this paper is to 
reveal not only the relationship between the psychosomatic effects and local air velocity, but also the relationship between face skin condition as a physical effect and the local air velocity over a 5 days period. The protocol was designed to use human biomarkers as indexes that could be collected noninvasively. SAA and salivary cortisol were used as the indexes of psychosomatic stress. Using salivary biomarkers has the advantage that it is non-invasive, which makes multiple sampling easy and does not introduce distress. SAA is known to increase slightly with increased flow rates of saliva, and large increments in amylase concentration have been observed during sympathetic control by Speirs et al.

[10]. Taking $\beta$-blockers significantly decreases the secretion of SAA, this provides direct evidence for the sensitivity of SAA to change in adrenergic activation [11]. Currently, it is considered that measurement of this SAA is a useful index of the plasma norepinephrine concentration under a variety of stressful conditions, since it appears that increased sympathetic nervous activity is a major stimulus of amylase secretion $[12,13]$. On the other hand, corticotrophin-releasing hormone $(\mathrm{CRH})$ is one of the most important mediators of the stress response, coordinating the adaptive behavioral and physiological changes that occur during stress [14]. Salivary cortisol has advantages for analysis of stress in that (i) these hormones have a simple relationship with CRH; (ii) the concentrations of these hormones correlate significantly between plasma and saliva [15]. Thus, diurnal variation of cortisol concentration is one of the most useful physiological indexes of chronic stress [16].

Total protein (TP) collected from the stratum corneum of human skin has been used as an index of dry skin condition. It has been demonstrated that dry skin is related to a slight increase in the rate of 
continuous shedding and renewal (epidermopoiesis) [17]. Tape stripping is established as a simple technique for sampling or evaluating the function of the stratum corneum by using adhesive in dermatological research $[18,19]$. The most commonly used tape stripping method utilizes the DSquame (Cuderm Corporation, Dallas, TX, USA). An instrument is on the market designed to indirectly measure the stratum corneum protein content on tape stripping [20].

In this paper, a continuous experiment over a 5 days period was conducted using 8 healthy young male adults $(22.4 \pm 0.7 \mathrm{yr}$, mean \pm standard deviation; SD) and 2 -types of airflow conditions from either a whole ceiling-type air conditioner (without local air velocity) and a commercialized concentrated exhaust air conditioner (normal-type air conditioner, with local air velocity), where changes in the biomarkers were monitored. Subjective evaluations were conducted on each subject using a selfassessed questionnaire on the environmental assessment. The experiments were performed between July and August in an experimental room where the room temperature was cooled using the air conditioners.

\section{Material and Methods}

\subsection{Whole ceiling-type air conditioner}

A whole ceiling-type air conditioner has a 3-dimensional knit fabric $\left(1.77 \mathrm{~m} \times 0.89 \mathrm{~m} \times 2\right.$ seats; $3.2 \mathrm{~m}^{2}$, Asahi Kasei Fibers Co., Japan) on the air outlet on the ceiling. The fabricated 3-dimensional knit fabric consists of a surface layer, a connecting fiber and a back layer (thickness $11.5 \mathrm{~mm}$, Fig. 1). When air pressure is applied on the surface layer of the 3-dimensional knit fabric, parallel-directed airflow is 
exhaled from the back layer.

The whole ceiling-type air conditioner consists of an air conditioner (S28FLV; $2.8 \mathrm{~kW}$ of cooling capacity, Daikin Industries Ltd., Japan), a blower tube and the 3-dimensional knit fabric and was installed in an evaluation room $(\mathrm{W} 3.7 \mathrm{~m} \times \mathrm{L} 7.1 \mathrm{~m} \times \mathrm{H} 2.7 \mathrm{~m}$, Fig.2a, c). This air conditioner provides an equalized temperature and relative humidity environment by generating a parallel-directed airflow flow using the 3-dimensional knit fabric, which is installed on the ceiling (Fig. 2a). An air conditioner without 3-dimensional knit fabric was used as the normal-type air conditioner for the comparison (Fig. 2b). The evaluation room has a window (W1.8 $\mathrm{m} \times \mathrm{H} 1.8 \mathrm{~m}$ ) and a door (W0.7 $\mathrm{m} \times \mathrm{H} 1.9 \mathrm{~m}$, Fig.2d). Eight sets of thermo-hygrometers $\left(\gamma_{\mathrm{h}}, \gamma_{\mathrm{m}}, \gamma_{\mathrm{l}}, \gamma_{\mathrm{o}}\right.$ and $\left.\gamma_{\mathrm{c}}\right)$ were placed on the inside, outside and a corridorside of the evaluation room. The mean air velocity was measured at the head of the subjects using an anemometer (Kanomax Japan, Inc., Japan).

\subsection{Subjects and informed consent}

We have limited the number of the subjects to 4 in a test because people usually feel uncomfortable to have a time with too many strangers in a room. Eight Japanese male adults subjects (aged between 21 and $23,22.4 \pm 0.7 \mathrm{yr}$ ) were enrolled in this study which was the maximum number in order to perform this evaluation in a summer season by using the same evaluation room. The mean BMI, weight, and height for the subjects were $25.2 \pm 4.2 \mathrm{~kg} / \mathrm{m}^{2}, 76.4 \pm 13.5 \mathrm{~kg}$ and $173.7 \pm 3.7 \mathrm{~cm}$, respectively. The study protocol was approved by the Ethical Committee of Iwate University. The study protocol was 
fully explained to all of the subjects in both spoken and written forms, specifically focusing on the purpose of the study, the precise procedures that would be used and any possible adverse effects. Signed, informed, consent was obtained from each subject who enrolled in the study.

\subsection{Subjective evaluation}

In order to evaluate the feeling of the subjects, a self-assessed questionnaire on the room's environment was set consisting of 7 adjectives: feel cool at head, feel cool at feet, feel cool in whole body, feel windy, feel dry, comfortable and sleepy. The applicability of the adjectives to current mood was marked by the subjects on a 10 point scale between agree $(+5)$, cannot say either or not $(0)$ and disagree (-

\section{5) (Table 1).}

\subsection{Salivary biomarkers}

SAA was analysed as an acute index of the sympathetic nervous system. The authors have manufactured a hand-held type SAA monitor (SAA monitor) which can be easily and quickly used for evaluating the activity of the sympathetic nervous system at any time [21, 22]. The time required for collection of saliva is approximately $30 \mathrm{~s}$, and it takes $30 \mathrm{~s}$ for analysis using the hand-held monitor; thus a total of 1 minute is sufficient to measure the SAA. The SAA monitor received approval in October 2007 from the Ministry of Health, Labor and Welfare in Japan to be sold for medical use in hospitals and is on the market (CM-2.1, Nipro Co., Japan). The enzyme activity was expressed as kU/l. 
Cortisol was analysed as a chronic index of stress. In order to collect a saliva sample for cortisol analysis, a cotton roll was placed under the tongue for $3 \mathrm{~min}$ and then placed in a sampling cup. Then the saliva samples were centrifuged and the supernatant was stored at $-20{ }^{\circ} \mathrm{C}$. Salivary cortisol was analysed using enzyme-linked immunosorbent assay kits (1-3002, Salimetrics LLC, PA, USA) and a plate reader (450 nm measurement wavelength, ARVO MX, PerkinElmer Inc., MA, USA). The concentration was expressed as $\mathrm{ng} / \mathrm{ml}$.

\subsection{Skin biomarker}

Two body sites were assessed on each subject. The upper cheek (drying-exposed) and back (relatively drying-protected) were used for the skin areas from which to collect the stratum corneum samples. The stratum corneum was collected using a D-Squame disk (D100, diameter of $22 \mathrm{~mm}$ ); this is termed as 'disk' hereforward. The disk was pressed on the skin surface using a disk applicator (D500, Cuderm Corporation, Dallas, TX, USA), after that it was pulled off the skin. Each disk was inserted into $750 \mu \mathrm{l}$ acetate buffer ( $4 \mathrm{mM}, \mathrm{pH} 5$ ) containing $0.1 \%$ triton $\mathrm{X}-100$. An ultrasonic wave was applied to the acetate buffer using an ultrasonic cleaner (2210DTH, Branson Ultrasonic Corporation, CT, USA) for 30

min at $37^{\circ} \mathrm{C}$. The dissolved solution was centrifuged to a five-times concentration using a centrifugal evaporator (CE1, HitachiKoki Co. Ltd., Tokyo, Japan) for $4 \mathrm{~h}$ at $37^{\circ} \mathrm{C}$. The TP of the sample solution (g/l) was analysed by the Lowry method using a colorimetric total protein assay kit (RC DC protein assay, Bio-Rad Laboratories, Inc., CA) and plate reader [23, 24]. Finally, the ratio of TP per disk area $\left(\mu \mathrm{g} / \mathrm{cm}^{2}\right)$ 
was calculated using the $150 \mu \mathrm{l}$ sample volume and $3.8 \mathrm{~cm}^{2}$ disk area.

\subsection{Experimental Protocol}

Prior to the experiment, the subjects were kept in smoke-free conditions for the whole previous day in order to avoid any psychosomatic effects. This experiment took place in the evaluation room between 10:00 am and 17:00 p.m. every day (Fig.3).

Subjects took a sitting position in the center of the evaluation room, and during the experiment talking was not permitted. The temperature of the evaluation room was controlled to set at $26^{\circ} \mathrm{C}$ using the whole ceiling-type air conditioner. SAA analysis and saliva sampling for the analysis of salivary cortisol were performed twice a day at the beginning and ending of the evaluation, in total 6 times for each $\left(\mathrm{A}_{1-6}\right.$,

$\mathrm{B}_{1-6}$, Fig.3). Stratum corneum sampling for the analysis of TP was performed once a day, in total 5 times $\left(\mathrm{C}_{1-5}\right)$. Before the subjects left the evaluation room, the subjects filled in the self-assessed questionnaire every day $\left(D_{1-5}\right)$. The subjects were allowed to leave the evaluation room when they need to use a toilet and have lunch. The subjects relaxed as much as possible. They performed desk work as they liked using a computer and/or book during the experiment.

The same experimental procedures were repeated under the normal-type air conditioner as control data on another week. To offset the effect of the experimental order, the subjects were divided into 2 groups and a crossover study was conducted. 


\subsection{Statistical analysis}

Within-group comparisons were performed using the Wilcoxon test (Statview 5.0; Abacus Concepts,

inc., CA). Unless otherwise stated, all data are expressed as mean \pm standard deviation (SD). A value of $p<0.01$ was taken to represent statistical significance.

\section{Influence of local air velocity}

\subsection{Environmental condition}

This experiment took place in a laboratory at Morioka, Iwate, Japan $\left(39.70^{\circ}\right.$ latitude and $141.13^{\circ}$ longitude) during July and August. The outside temperature in the daytime ranged between $16.9-$ $31.5^{\circ} \mathrm{C}$, the mean value was $25.4^{\circ} \mathrm{C}$. The outside relative humidity in the daytime ranged between $50-$ $95 \%$, the mean value was $71 \%$.

The mean values of temperatures of the evaluation room were $24.7\left(\gamma_{1}\right), 25.5\left(\gamma_{\mathrm{m}}\right)$ and $26.1^{\circ} \mathrm{C}\left(\gamma_{\mathrm{h}}\right)$ under the conditions of the whole ceiling-type air conditioner. The mean value of temperatures of the evaluation room were $25.2\left(\gamma_{1}\right), 25.8\left(\gamma_{\mathrm{m}}\right)$ and $26.4{ }^{\circ} \mathrm{C}\left(\gamma_{\mathrm{h}}\right)$ under the conditions of the normal-type air conditioner. The temperature conditions were maintained at $25.6 \pm 0.9^{\circ} \mathrm{C}$ in both air conditioners. The room temperature was controlled to be a similar value to the mean value of the daytime outside temperature. The mean relative humidity of the evaluation room was maintained at 44.3 and $48.8 \%$ in the whole ceiling-type and the normal-type air conditioners, respectively. A significant difference was not observed between them. 
The mean air velocity was $0.1 \mathrm{~m} / \mathrm{s}$ under the conditions of the normal-type air conditioner. The mean air velocity under the conditions of the whole ceiling-type air conditioner cannot be measured correctly $(<0.1 \mathrm{~m} / \mathrm{s})$.

\subsection{Subjective evaluation}

The total scores of feel cool at head and feel cool in whole body were significantly different between the 2 air conditioners $(p<0.01)$, the subjects complained of feeling cold under the normal-type air conditioner (Fig. 4). On the other hand, the total scores of feel cool at feet showed no significant difference. The total scores of feel windy were significantly different between the 2 air conditioners $(p<$ 0.01), the subjects complained feeling windy under the normal-type air conditioner.

The total scores of feel dry were significantly different between the 2 air conditioners $(p<0.01)$, the subjects complained feeling dry under the normal-type air conditioner. The total scores of comfortable was significantly different between the 2 air conditioners $(p<0.01)$, the subjects complained more comfortable at the whole ceiling-type air conditioner. The total scores of sleepy showed no significant difference. Based on these results, subjects complained of feeling cool, windy, dry and uncomfortable under the normal-type air conditioner in the subjective evaluation.

\subsection{Salivary biomarkers}

The SAA ranged between 10 and $69 \mathrm{kU} / \mathrm{l}(\min -\max )$, and the mean value was $26.2 \pm 12.1 \mathrm{kU} / \mathrm{l}$. A 
significant difference was not observed between the 2 air conditioners $(p>0.01)$. There were very wide ranges of the SAA between different individuals. Therefore the time-course changes of SAA were calculated using the normalized values of the initial day (Day 1, Fig.5). After day 3, the mean SAA measured under the whole ceiling-type air conditioner kept fluctuating between $155-205 \%(185 \pm 32 \%)$.

On the other hand, the mean SAA of the normal-type air conditioner kept fluctuating more widely between $104-188 \%(164 \pm 60 \%)$.

The salivary cortisol ranged between 0.44 and $10.84 \mathrm{ng} / \mathrm{ml}$ (min. and max.), and the mean value was $2.01 \pm 0.15 \mathrm{ng} / \mathrm{ml}$. The salivary cortisol in the evening was statistically lower than in the morning for both air conditioners $(p<0.01)$. Therefore the time-course changes of salivary cortisol are given as the difference between morning and evening levels ( $\Delta$ CORT, Fig.6). The $\Delta$ CORT did not show a significant difference between the 2 air conditioners on day 1 . However, the $\Delta$ CORT of the normal-type air conditioner showed statistically higher values than those of the whole ceiling-type air conditioner during day 3 and 5.

\subsection{Skin biomarker}

The TP ranged between $1.81-21.0 \mu \mathrm{g} / \mathrm{cm}^{2}$, and the mean value was $8.0 \pm 3.35 \mu \mathrm{g} / \mathrm{cm}^{2}$ in all of the stratum corneum samples. The mean TP of the upper cheek (drying-exposed) and the back (relatively drying-protected) were $7.32 \pm 2.68$ and $8.77 \pm 3.78 \mu \mathrm{g} / \mathrm{cm}^{2}$, respectively. In order to evaluate the environmental influence on skin, the TP was compared between the initial (day 1 \& 2) and the later 
periods (day 4 \& 5) (Fig.7). Firstly, a significant difference of TP was not observed between the 2 air conditions $(p>0.01)$. However, the TP of the upper cheek for the normal-type air conditioner showed statistically higher values than for the whole ceiling-type air conditioner $(p<0.01)$, whilst a significant difference in the TP from the back was not observed between the 2 air conditions $(p>0.01)$.

\section{Discussion}

A continuous experiment for a 5 days period was conducted using 8 healthy young male adults in order to determine both the psychosomatic and the physical effects of local air velocity from an air conditioner. When the temperature was maintained at $25.6 \pm 0.9^{\circ} \mathrm{C}$ with both air conditioners, the subjects complained of feeling cold, windy and uncomfortable at the normal-type air conditioner in the subjective evaluation. It is reported that rapid temporary cooling to the face affects thermal sensation [25]. It is widely accepted that local air velocity and the temperature is an important thermal factor regarding thermal sensation and comfort [26]. In this study we have also demonstrated the strong impact of temperature sensation by the face influences the whole impression of temperature as determined by subjective evaluation. The subjects were more comfortable at the whole ceiling-type air

conditioner. Thus, it was considered that both sensations of feeling cool at the head and windy were reflected for the scores of feel cool in whole body and comfortable because the subjects did not complain of feeling cool at their feet.

The time-course changes of SAA showed different profiles between the 2 air conditioners. The SAA 
of the normal-type air conditioner kept fluctuating more widely than the whole ceiling-type air conditioner showing that the normal-type air conditioner gave more stimulation to the sympathetic nervous system. This tendency agreed with the results of subjective evaluation which showed the subjects felt more comfortable under the whole ceiling-type air conditioner.

The decreased level of the salivary cortisol in a day $(\Delta \mathrm{CORT})$ for the normal-type air conditioner showed a statistically higher value than that of the whole ceiling-type air conditioner. It was indicated that the breakdown of the cortisol in a subject under the normal-type air conditioner was higher than with the whole ceiling-type air conditioner. Cortisol serves to mobilize and replenish energy stores; it contributes to increased arousal, vigilance, and focused attention [14]. These effects may contribute during an acute response to stress. However, excessive and sustained cortisol secretion due to rapid breakdown in vivo can have serious adverse effects linked to some kinds of disease [27]. It is possibe that reducing the local air velocity may induce breakdown of the cortisol, as a result it provided more healthy conditions psychosomatically over the long-term.

When the subjects were exposed to the air conditioners for a one third period of a day (10:00 - 17:00) for a week, the significant difference identified between the upper cheek and the back. It was indicated that one week exposure to windy conditions influenced the drying of facial skin because significant differences were observed between the initial and the later periods. The physical effects of the TP of drying-exposed areas agreed well with the subjective evaluation. 


\section{Conclusions}

The main finding reported in the manuscript is that air movement at low velocity as generated by the low impulse air distribution can provides comfortable indoor environment compared to environment with locally applied air movement at high velocity and pressure. Furthermore the results indicate a possibility negative impact of decreased air velocity on skin dryness. Moreover, it was expected that the subject's environmental stimulation can be decreased by using the whole ceiling-type air conditioner.

In future, more studies are necessary to evaluate several other important factors such as air temperature, relative humidity and pollution in inhaled air.

ACKNOWLEDGMENT: Part of this research was supported by the FY 2007 - 2009 Grants-in-Aid for Scientific Research C from the Japan Society for the Promotion of Science (No. 22500400), Japan. 


\section{References}

[1] Mai HK, Chan DW, Burnett J. Dynamic evaluation of airflow rates for a variable air volume system serving an open-plan office. Indoor Air 2003; 13(3): 311-2.

[2] Tham KW, Willem HC. Room air temperature affects occupants' physiology, perceptions and mental alertness. Building and Environment 2010; 45(1): 40-44.

[3] Toftum J. Central automatic control or distributed occupant control for better indoor environment quality in the future. Building and Environment 2010; 45(1): 23-28.

[4] Bauman FS, Arens EA, Tanabe S, Zhang H, Baharlo A. Testing and optimizing the performance of a floor-based task conditioning system. Energy and Buildings 1995; 22(3): 173-86.

[5] Liu W, Lian Z, Yao Y. Optimization on indoor air diffusion of floor-standing type room airconditioners. Energy and Buildings 2008; 40(2): 59-70.

[6] Amai H, Tanabe S, Akimoto T, Genma T, Thermal sensation and comfort with different task conditioning systems. Building and Environment 2007; 42(12): 3955-64.

[7] ZhangH, Arens E, Kim D, Buchberger E, Bauman F, Huizenga C. Comfort, perceived air quality, and work performance in a low-power task-ambient conditioning system. Building and Environment 2010; 45(1): 29-39.

[8] Akimoto T, Tanabe S, Yanai T, Sasaki M. Thermal comfort and productivity - Evaluation of workplace environment in a task conditioned office. Building and Environment 2010; 45(1): 45-50.

[9] Tahara Y, Morito N, Nishimiya H, Yamagishi H, Yamaguchi M. Evaluation of environmental and 
physiological factors of a whole ceiling-type air conditioner using a salivary biomarker. Building and Environment 2009; 44(6): 1156-1161.

[10] Speirs RL, Herring J, Cooper WD, Hardy CC, Hind CR. The influence of sympathetic activity and isoprenaline on the secretion of amylase from the human parotid gland. Archives Oral Biology 1974; 19: 747-752.

[11] Stegeren, A, Rohleder, N, Everaerd, W, Wolf, OT. Salivary alpha amylase as marker for adrenergic activity during stress: effect of betablockade. Psychoneuroendocrinology 2006; 31: 137-141.

[12] Jenkins GN. The physiology and biochemistry of the mouth. Fourth Edition. Blackwell Scientific Publications; 1978, p.284-359.

[13] Ugolev AM, Laey PD, Iezuitova NN, Rakhimov KR, Timofeeva NM, Stepanova AT, Membrane digestion and nutrient assimilation in early development. Ciba Found Symposium 1979; 1618(70): 221-246.

[14] Charney DS. Psychobiological mechanisms of resilience and vulnerability: implications for successful adaptation to extreme stress. American Journal of Psychiatry 2004; 161: 195-216.

[15] Vining RF, McGinley RA, Maksvytis JJ, Ho KY. Salivary cortisol: a better measure of adrenal cortical function than serum cortisol. Annals of Clinical Biochemistry 1983; 20: 329-335.

[16] Nakajima Y, Takahashi T, Yamaguchi M. Diurnal variation of salivary cortisol and amylase activity in fatigued state. In: Brebbia CA editor. Environmental Health Risk V. WIT Press; 2009, p. 381390. 
[17] Rawlings AV. Trends in stratum corneum research and the management of dry skin conditions. International Journal of Cosmetic Science 2003; 25(1-2): 63-95.

[18] Pinkus H. Examination of the epidermis by the strip method of removing horny layers. I. Observations on thickness of the horny layer, and on mitotic activity after stripping. Journal of Investigative Dermatology 1951; 16(6): 383-386.

[19] Blank IH. Further observations on factors which influence the water content of the stratum corneum. Journal of Investigative Dermatology 1953; 21(4): 259-271.

[20] Voegeli R, Heiland J, Doppler S, Rawlings AV, Schreier T. Efficient and simple quantification of stratum corneum proteins on tape strippings by infrared densitometry. Skin Research and Technology 2007; 13(3): 242-251.

[21] Yamaguchi M, Kanemori T, Kanemaru M, Takai N, Mizuno Y, Yoshida H. Performance evaluation of salivary amylase activity monitor. Biosensors and Bioelectronics 2004; 20(3): 491-497.

[22] Yamaguchi M, Deguchi M, Wakasugi J, Takai N, Higashi T, Mizuno Y. Hand-held monitor of sympathetic nervous system using salivary amylase activity and driver fatigue assessment. Biosensors and Bioelectronics 2006; 21(7): 1007-1014.

[23] Lowry OH, Rosebrough NJ, Farr AL, Randall RJ. Protein measurement with the Folin phenol reagent. Journal of Biological Chemistry 1951; 193(1): 265-275.

[24] Dreher F, Arens A, Hostýnek JJ, Mudumba S, Ademola J, Maibach HI. Colorimetric method for quantifying human Stratum corneum removed by adhesive-tape stripping. Acta Dermato- 
Venereologica 1998; 78(3): 186-189.

[25] Kato M, Sugenoya J, Matsumoto T, Nishiyama T, Nishimura N, Inukai Y, Okagawa T, Yonezawa H. The effects of facial fanning on thermal comfort sensation during hyperthermia. Pflügers Archiv-European Journal of Physiology 2001; 443(2): 175-179.

[26] Yamashita K, Matsuo J, Tochihara Y, Kondo Y, Takayama S, Nagayama H. Thermal sensation and comfort during exposure to local airflow to face or legs. Journal of Physiological Anthropology and Applied Human Science 2005; 24(1): 61-66.

[27] Karlamangla AS, Singer BH, McEwen BS, Rowe JW, Seeman TE. Allostatic load as a predictor of functional decline. MacArthur studies of successful aging. Journal of Clinical Epidemiology 2002; 55(7): 696-710. 
Figure \& Table Legends

Fig. 1. A 3-dimensional knit fabric for a whole ceiling-type air conditioner used for without airflow to face (Asahi Kasei Fibers Co., Japan).

Fig. 2. Arrangement of an evaluation room for local airflow to face (Units in $\mathrm{m}$ ), $\alpha$ : 3-dimensional knit fabric, $\beta$ : outlet hole, $\gamma: 8$ sets of thermo-hygrometers $\left(\gamma_{\mathrm{h}}, \gamma_{\mathrm{m}}, \gamma_{\mathrm{l}}, \gamma_{\mathrm{o}}\right.$ and $\left.\gamma_{\mathrm{c}}\right), \gamma_{\mathrm{h}}, \gamma_{\mathrm{m}}, \gamma_{1}$ : thermohygrometer of inside, $\gamma_{0}$ : thermo-hygrometer of outside, $\gamma_{c}$ : thermo-hygrometer of corridor-side, $\delta$ : pole, $\varepsilon:$ window and aluminium horizontal blind, $\zeta:$ desk, $\eta$ : chair.

Fig. 3. Experimental protocol for local air flow to face, A: saliva collection and analysis of SAA, B : saliva collection for cortisol analysis, C: collection of stratum corneum for TP analysis, D: selfassessed questionnaire, $\Delta$ : enter evaluation room, $\boldsymbol{\Delta}$ : leave evaluation room.

Fig. 4. Comparison of the mean values of a 5 days period between the 2 air-conditioners for each adjective $(*: p<0.01)$.

Fig. 5. Time-course changes of standardized mean SAA (m: morning, e: evening).

Fig. 6. Time-course changes of salivary cortisol concentrations determined by subtracting evening from morning readings (NS: not significant).

Fig. 7. Comparison of TP between the initial (day $1 \&$ day 2) and the later (day $4 \&$ day 5) periods.

Table 1 Self-assessed questionnaire on the room's environment consisting of 7 adjectives. 
Table1 Self-assessed questionnaire on the room's environment consisting of 7 adjectives.

\begin{tabular}{l|lll}
\hline \hline Questionnaire & \multicolumn{1}{|c}{+5} & 0 & \multicolumn{1}{c}{-5} \\
\hline Feel cool at head & Cool & $\leftarrow$ Hot \\
Feel cool at feet & Cool & $\longleftrightarrow$ Hot \\
Feel cool in whole body & Cool & $\longleftarrow$ Hot \\
Feel windy & Agree & $\longleftrightarrow$ Disagree \\
Feel dry & Agree & $\longleftrightarrow$ Disagree \\
Comfortable & Agree & $\longleftrightarrow$ Disagree \\
Sleepy & Agree & $\longrightarrow$ Disagree \\
\hline \hline
\end{tabular}




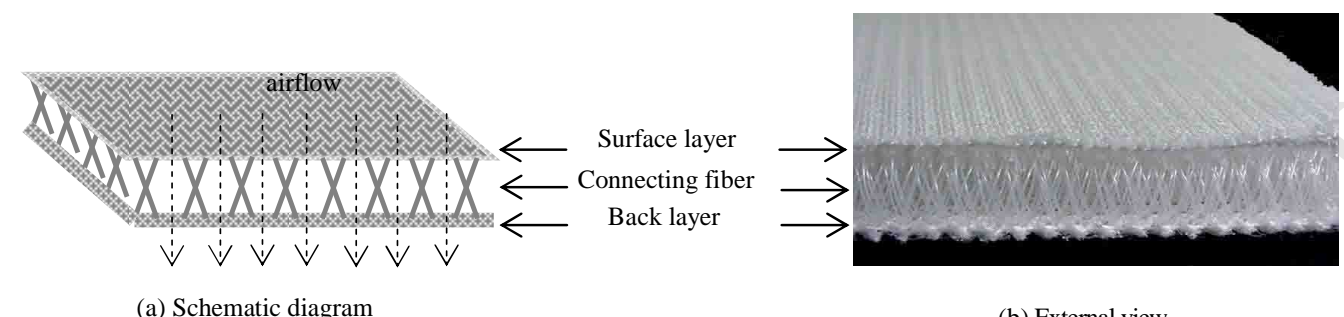

(a) Schematic diagram

(b) External view

Fig. 1. A 3-dimensional knit fabric for a whole ceiling-type air conditioner used for without airflow to face (Asahi Kasei Fibers Co., Japan). 


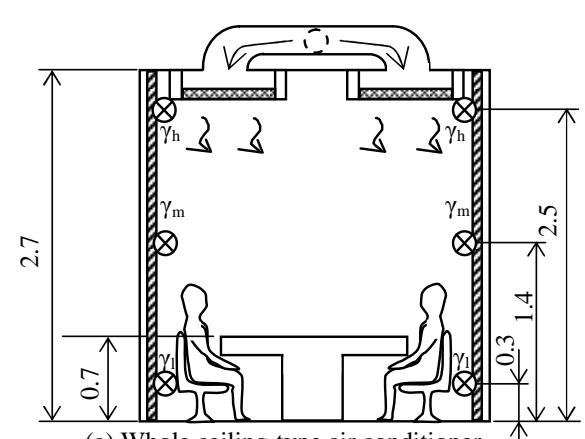

(a) Whole ceiling-type air conditioner (Without airflow to face)

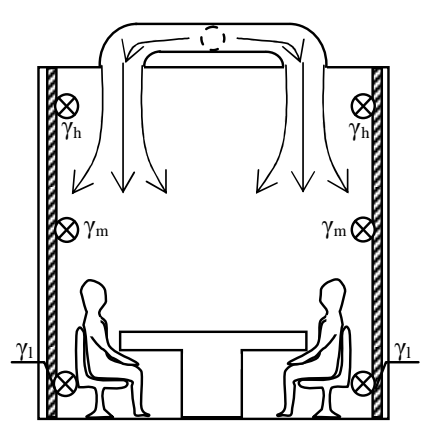

(b) Normal-type air conditioner (With airflow to face)

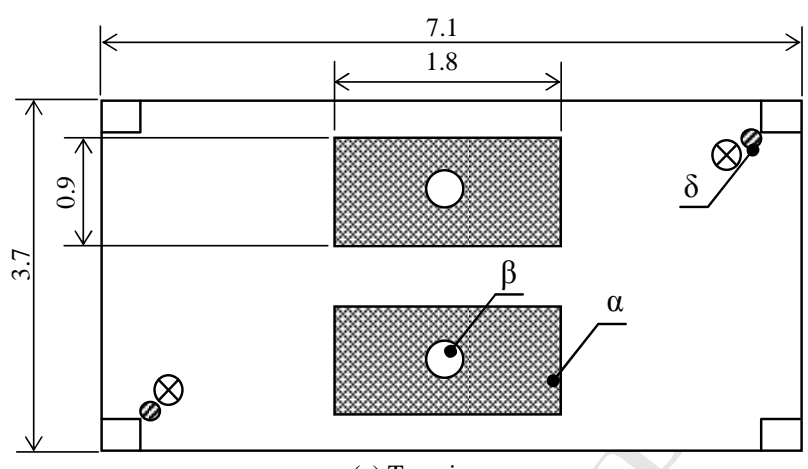

(c) Top view

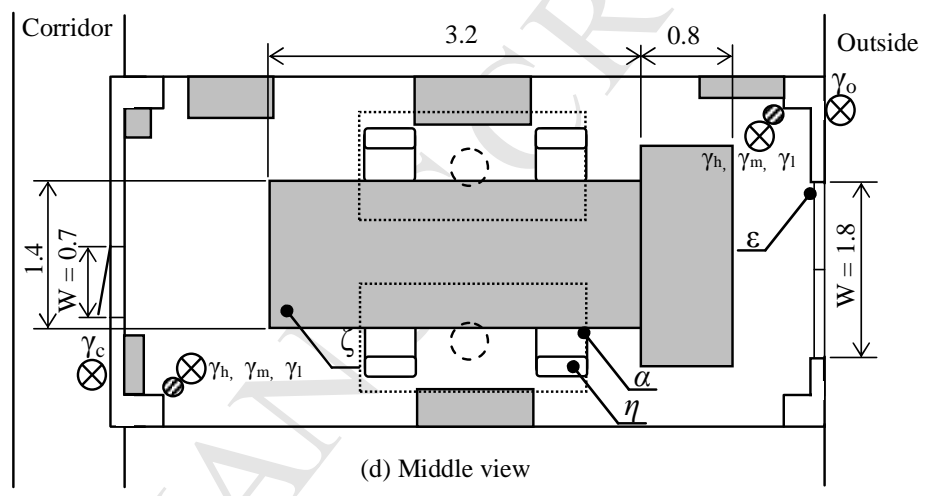

Fig.2 Arrangement of an evaluation room for local airflow to face (Units in m), $\alpha$ : 3 -dimensional knit fabric, $\beta$ : outlet hole, $\gamma: 8$ sets of thermo-hygrometers $\left(\gamma_{\mathrm{h}}, \gamma_{\mathrm{m}}, \gamma_{1}, \gamma_{\mathrm{o}}\right.$ and $\left.\gamma_{\mathrm{c}}\right), \gamma_{\mathrm{h}}, \gamma_{\mathrm{m}}, \gamma_{1}$ : thermo-hygrometer of inside, $\gamma_{\mathrm{o}}$ : thermo-hygrometer of outside, $\gamma_{\mathrm{c}}$ : thermo-hygrometer of corridor-side, $\delta$ : pole, $\varepsilon$ : window and aluminium horizontal blind, $\zeta$ : desk, $\eta$ : chair. 

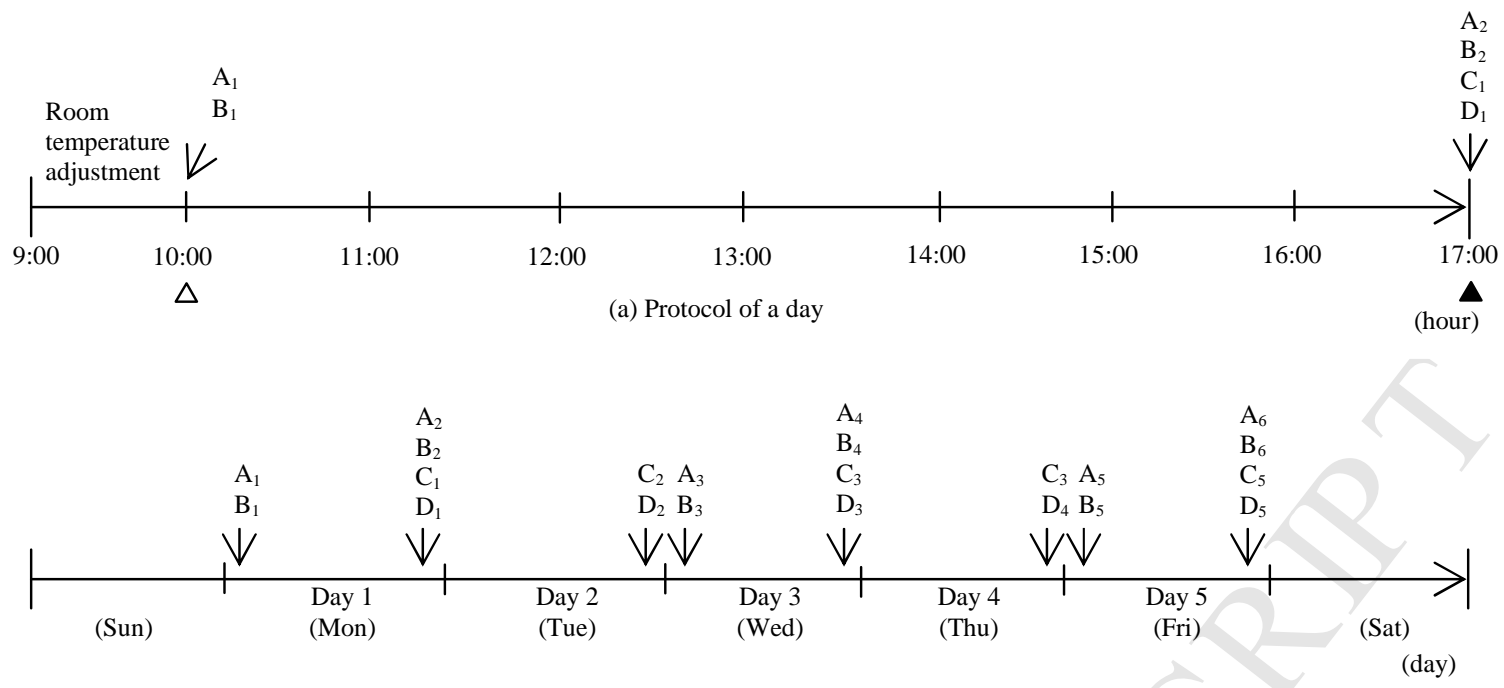

(b) Protocol of a week

Fig.3. Experimental protocol for local air flow to face, A: saliva collection and analysis of SAA, B : saliva collection for cortisol analysis, C: collection of stratum corneum for $T P$ analysis, D: self-assessed questionnaire, $\triangle$ : enter evaluation room, $\boldsymbol{\Delta}$ : leave evaluation room. 


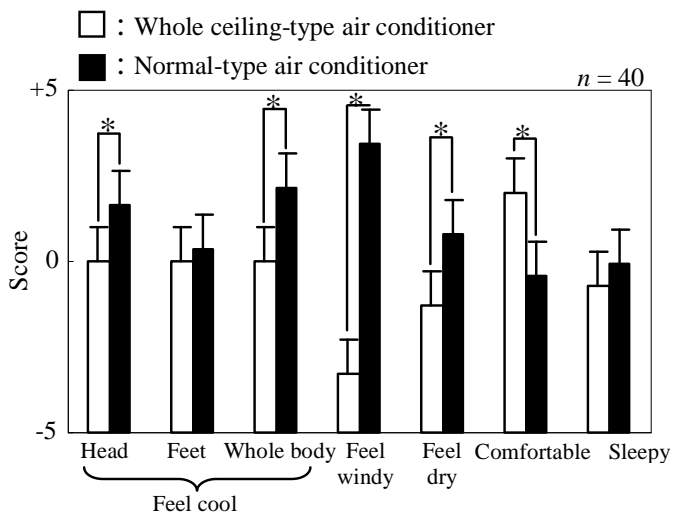

Fig.4. Comparison of the mean values of a 5 days period between the 2 air-conditioners for each adjective $(*: p<0.01)$. 


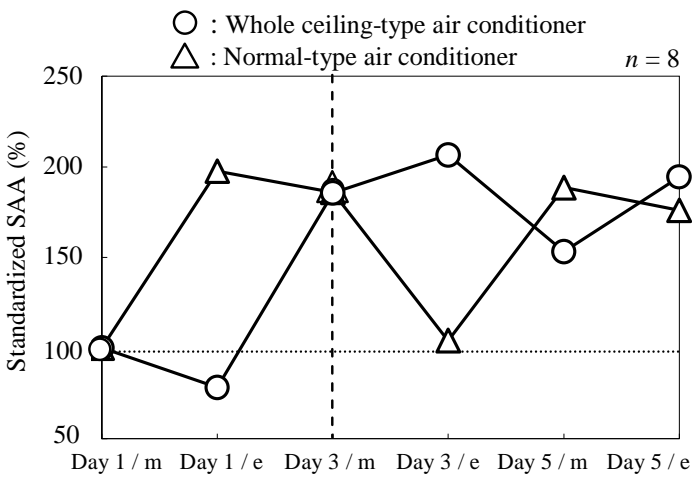

Fig.5. Time-course changes of standardized mean SAA (m: morning, e: evening). 


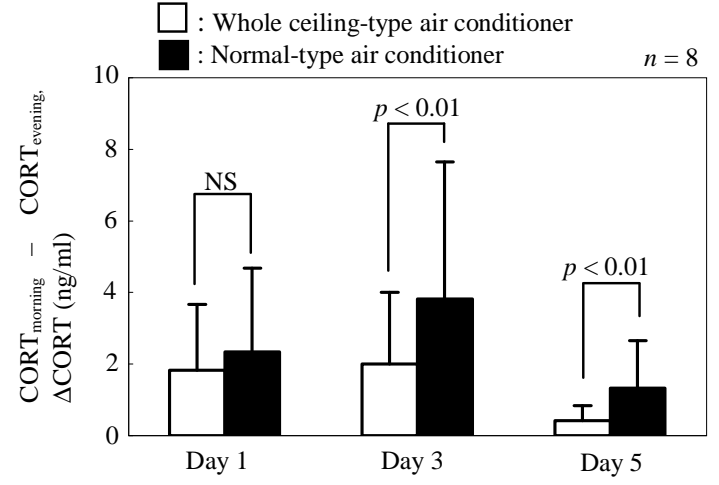

Fig.6. Time-course changes of salivary cortisol concentrations determined by subtracting evening from morning readings (NS: not significant). 